\title{
Association of family income with BMI from childhood to adult life: a birth cohort study
}

\author{
Denise P Gigante ${ }^{1,2, *}$, Cesar G Victora ${ }^{2}$, Alícia Matijasevich², Bernardo L Horta ${ }^{2}$ and \\ Fernando C Barros ${ }^{2,3}$ \\ ${ }^{1}$ Nutrition Departament, Universidade Federal de Pelotas, Marechal Deodoro, 1160 - 3o. andar, Pelotas, RS \\ 96020-220, Brazil: ${ }^{2}$ Postgraduate Program in Epidemiology, Universidade Federal de Pelotas, Pelotas, RS, \\ Brazil: ${ }^{3}$ Postgraduate Program in Health and Behavior, Universidade Católica de Pelotas, Pelotas, RS, Brazil
}

Submitted 18 July 2011: Final revision received 13 February 2012: Accepted 2 May 2012: First published online 4 July 2012

\begin{abstract}
Objective: To investigate the association of family income at birth with BMI among young adults who have been followed since birth.

Design: A birth cohort study.

Setting: In 1982, all children born in Pelotas, southern Brazil, were included in a perinatal survey and visited at ages 1, 2, 4, 15, 18-19 and 23 years.

Subjects: Cohort members ( $n$ 4297) were traced and interviewed in 2004-2005. In all follow-ups, participants were weighed and measured, and BMI and prevalence of obesity were calculated for each age. Family income was obtained in minimum wages in 1982 and as a continuous variable, in reais, in later followups. Skin colour was self-reported in 2004-2005.

Results: Mean BMI and prevalence of obesity differed between males and females. In males, a direct relationship was found throughout life and among females this relationship was modified by age. During childhood, BMI was higher among girls from higher income groups and this association was inversed at age 23 years. At this same age, mean BMI among black women was $1.3 \mathrm{~kg} / \mathrm{m}^{2}$ higher than among white women, even after adjustment for current family income.

Conclusions: The findings show in men that the relationship between income and BMI is similar to that seen in less developed areas, whereas among adult women the relationship is similar to that observed in developed countries. In addition to the effect of socio-economic status, skin colour also has an influence on the BMI of adult women.
\end{abstract}



Keywords

BMI Cohort studies
Cross-sectional studies from both developed and developing countries have shown that the prevalence of obesity increases from childhood to adult age ${ }^{(1)}$. However, factors related to the occurrence of obesity at different ages may vary depending on a country's level of development. The relationship between socio-economic status and obesity has been the subject of some reviews ${ }^{(2-4)}$. These studies, which update and extend the review by Sobal and Stunkard ${ }^{(5)}$, showed that the current scenario differs slightly from the conditions found in 1989, with the inverse association between obesity and socio-economic level now being present among women from both developed and developing countries. Results among men are not as consistent, although a trend towards a similar association has been observed in countries with high human development index $(\mathrm{HDI})^{(3)}$ as well as in developing countries undergoing an increase in gross domestic product ${ }^{(4)}$. Whereas these latter two reviews include mainly cross-sectional studies, Ball and Crawford ${ }^{(2)}$ reviewed the effect of different socio-economic indicators on weight change in adults. These authors concluded that the risk of weight gain is higher among individuals of lower socio-economic status compared with those of higher status ${ }^{(2)}$. It should also be noted that these reviews focused primarily on the relationship between socio-economic status and obesity among adults. Regarding childhood factors associated with the appearance of obesity in adult age, the authors of a different review ${ }^{(6)}$ concluded that there is a consistent association between low socio-economic status in early life and increased obesity during adulthood. Given the abundance of definitions of overweight and obesity for children and adolescents, the literature is remarkably scarce in studies of their association with socio-economic variables. Using Cole et al.'s criteria ${ }^{(7)}$, Wang et $a l^{(8)}$ evaluated trends in child and adolescent overweight in countries with different levels of development, i.e. Brazil, USA, China and

*Corresponding autbor: Email denise.epi@gmail.com

(C) The Authors 2012. The online version of this article is published within an Open Access environment subject to the conditions of the Creative Commons Attribution-NonCommercial-ShareAlike licence $<$ http://creativecommons.org/licenses/by-nc-sa/3.0/ $>$. The written permission of Cambridge University Press must be obtained for commercial re-use. 
Russia. Their study showed that prevalences increased in the last decades of the 20th century in the first three countries, whereas in Russia overweight decreased during the 1990s. Whereas such increase was even across all income groups in China, it was greater among the rich in Brazil and among the poor in the $\mathrm{USA}^{(8)}$. A review of studies published between January 1980 and October 2005 showed that prevalence of childhood overweight increased in almost all of twenty-seven countries from which information was available, with the exception of school-aged children in Russia and Poland and infants and pre-school children in low-income countries. Overweight and obesity increased primarily in developed regions and among urban populations $^{(9)}$.

In addition to differences between men and women in terms of the effect of socio-economic status on obesity, there is some evidence for a possible effect of skin colour on this association ${ }^{(10,11)}$.

The aim of the present article was to investigate the association of family income at birth with BMI at different follow-up ages among black and white men and women belonging to the 1982 Pelotas birth cohort.

\section{Materials and methods}

The study began with a perinatal survey of all births that took place in 1982 in maternity facilities of the city of Pelotas, southern Brazil ${ }^{(12)}$. A questionnaire to gather information on socio-economic, demographic and healthrelated variables was administered to mothers while still in the maternity ward. Mothers were also weighed and measured, and the 5914 live babies whose families resided in the urban area of Pelotas were weighed, although length was not obtained at this stage of the study.

These children were subsequently visited at their homes on different occasions, and the methods used in these follow-ups have been described elsewhere ${ }^{(13-15)}$. In 1983, children born between January and April 1982 were visited, weighed and measured, and mothers answered a questionnaire that included information on health during the first year of life. The two subsequent follow-ups (1984 and 1986) followed censuses of the entire municipality conducted by the research team as an attempt to locate all children approximately 2 and 4 years of age, respectively, born in maternity facilities in the city of Pelotas. In 1997 and 2001, we attempted to trace roughly one-quarter of all cohort members identified in seventy of the city's 259 census tracts. In 2000, taking advantage of mandatory military enlistment for 18-year-old males, all recruits belonging to the 1982 cohort were identified and interviewed upon enlistment.

In 2004-2005 we conducted a further follow-up of the entire cohort, locating participants, now aged approximately 23 years, by means of a census of all of the city's households among other search strategies. These additional strategies also allowed us to trace cohort members who had moved out of Pelotas. For follow-ups conducted from childhood to adulthood, we used portable scales (CMS and SECA) and anthropometers (built locally) to obtain measures of weight and height, respectively. Anthropometric measurements were obtained using the techniques proposed by Lohmann et $a l^{(16)}$ and the interviewers were standardized according to these techniques. All methods were standardized, and quality control measures including regular scale calibration, repetition of $5 \%$ of interviews and double data entry were also employed.

Verbal informed consent was obtained from guardians in the initial stages of the study. More recent stages were approved by the University of Pelotas Research Ethics Committee, affiliated with the National Research Ethics Council (CONEP), and written informed consent was obtained from all participants.

The outcome of the present study is BMI, calculated by dividing weight in kilograms by the square of height in metres, both obtained during each follow-up between infancy and 23 years of age. BMI values obtained in each of the follow-ups were treated as continuous variables in all analyses. For prevalence of obesity, we used the $2 Z$-score cut-off for BMI/age based on the WHO growth curves for children and adolescents ${ }^{(17,18)}$ as well as those proposed by Cole et al. ${ }^{(7)}$. Prevalence of obesity at 23 years was defined as BMI equal to or greater than $30 \cdot 0 \mathrm{~kg} / \mathrm{m}^{2}$ at the 2004-2005 follow-up. ANOVA was used to compare means of different family income groups (variable constructed by adding all incomes of household members at each follow-up, expressed as minimum wages or reais and classified in quintiles). In order to evaluate the influence of inequity on BMI at different ages, we calculated the slope index of inequity (SII). This index has been used to evaluate the magnitude of socio-economic inequities with respect to a given outcome. It also has the advantage of comparing the effect of different socio-economic variables or of the same variable throughout life. This index was estimated by means of a linear regression equation calculated based on the level of the outcome in each quintile of family income, and expresses the estimated difference in terms of BMI between the highest and lowest quintiles of the socio-economic distribution ${ }^{(19)}$.

Skin colour was self-reported during the 2004-2005 follow-up according to the categories proposed by the Brazilian Institute of Geography and Statistics. We considered as 'black' (negro) individuals who self-classified as 'black' (preto) or 'mixed' (pardo). To determine the effect of skin colour on BMI at each of the follow-ups, we used linear regression, both crude and adjusted for family income at the respective follow-up.

\section{Results}

Success rates for each of the follow-ups have been described previously ${ }^{(13-15)}$. In 2004-2005 we were able to 
Table 1 Mean and standard deviation for BMI $\left(\mathrm{kg} / \mathrm{m}^{2}\right)$ in the different follow-ups of the 1982 birth cohort study, according to sex. Pelotas, southern Brazil, 1982 to 2004-2005

\begin{tabular}{|c|c|c|c|c|c|c|c|c|}
\hline \multirow[b]{2}{*}{ Follow-up } & \multirow[b]{2}{*}{ Age (years) } & \multicolumn{3}{|c|}{ Males } & \multicolumn{3}{|c|}{ Females } & \multirow[b]{2}{*}{$P$} \\
\hline & & $n$ & Mean & SD & $n$ & Mean & SD & \\
\hline 1983 & 1 & 714 & $17 \cdot 8$ & $1 \cdot 6$ & 743 & $17 \cdot 2$ & $1 \cdot 5$ & $<0.001$ \\
\hline 1984 & 2 & 2524 & $17 \cdot 1$ & $1 \cdot 4$ & 2406 & $16 \cdot 8$ & $1 \cdot 4$ & $<0.001$ \\
\hline 1986 & 4 & 2426 & $16 \cdot 4$ & 1.5 & 2313 & $16 \cdot 2$ & $1 \cdot 5$ & $<0.001$ \\
\hline 1997 & 15 & 559 & $20 \cdot 8$ & $3 \cdot 6$ & 513 & $21 \cdot 5$ & $3 \cdot 6$ & 0.002 \\
\hline 2000 & 18 & 2228 & $22 \cdot 3$ & $3 \cdot 7$ & & & & \\
\hline 2001 & 19 & & & & $450^{*}$ & $22 \cdot 4$ & 4.9 & \\
\hline 2004-2005 & 23 & 2206 & $23 \cdot 8$ & $4 \cdot 1$ & $1992^{*}$ & $23 \cdot 4$ & $4 \cdot 7$ & 0.009 \\
\hline
\end{tabular}

*Women pregnant at the time of the interview were excluded.

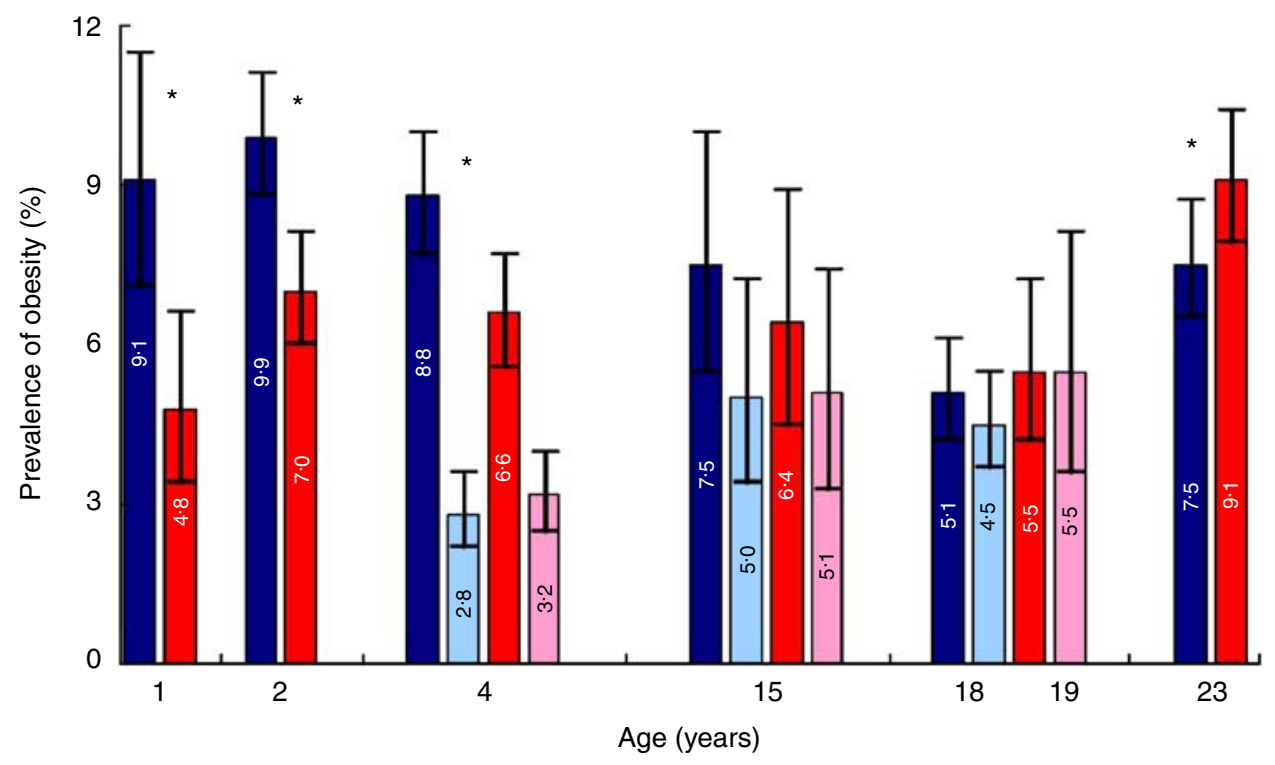

Fig. 1 (colour online) Prevalence of obesity by age according to criteria of $\mathrm{WHO}^{(17,18)}$ ( $\square$, males; $\square$, females) and Cole et al. ${ }^{(7)}$ ( $\square$, males; $\square$, females). Pelotas, southern Brazil, 1982 to 2004-2005. Values are means with standard deviations represented by vertical bars. ${ }^{*}$ Mean obesity prevalence was significantly different between males and females $\left(\chi^{2}\right.$ test): $P<0.05$

interview $77 \%$ of all cohort members. In general, individuals born to middle-class families were easier to trace than those born in either the upper or the lower end of the social distribution. There were no consistent differences in follow-up according to sex, birth weight or skin colour. Mean BMI at age 1 year was higher for those who were followed up until adulthood $\left(17 \cdot 6 \mathrm{~kg} / \mathrm{m}^{2} ; 95 \%\right.$ CI $17 \cdot 5,17 \cdot 7)$ than for the cohort as a whole $\left(17 \cdot 3 \mathrm{~kg} / \mathrm{m}^{2}\right.$; $95 \%$ CI $17 \cdot 1,17 \cdot 5)$, but this difference was not observed for the follow-ups at 2 or 4 years.

We obtained anthropometric measurements for almost the entirety of interviewed individuals (99.7\%; Table 1). All women who were pregnant at the time of the interview were excluded from the analysis (twenty-three in 2001 and ninety in 2004-2005). Table 1 also shows that mean BMI was higher among males of all ages and that, even though levels were higher at 2 years than at 4 years, there was an increase in mean BMI after 4 years of age. This difference between males and females can also be observed with respect to the prevalence of obesity at different ages (Fig. 1). Whereas obesity was more frequent among males during childhood, prevalence at 23 years was higher among females.

An analysis of the relationship between BMI at the various follow-ups and skin colour showed no differences among males (Table 2). However, mean BMI was higher among females with white compared with black skin at ages 2 and 4 years whereas the reverse was true at age 23 years, when black women were on average $1.4 \mathrm{~kg} / \mathrm{m}^{2}$ heavier than white women (Table 2).

The effect of family income on BMI at the various follow-ups is presented in Table 3 for males and Table 4 for females. A direct relationship between family income and BMI was observed among males of all ages (Table 3) and among females during childhood. On the other hand, an inverse association between income and BMI was observed 
Table 2 Mean and standard deviation for BMI $\left(\mathrm{kg} / \mathrm{m}^{2}\right)$ among males and females in the different follow-ups of the 1982 birth cohort study, according skin colour. Pelotas, southern Brazil, 1982 to 2004-2005

\begin{tabular}{|c|c|c|c|c|c|c|c|c|c|c|c|c|c|c|}
\hline \multirow[b]{3}{*}{ Age (years) } & \multicolumn{6}{|c|}{ Males } & \multirow[b]{3}{*}{$P$} & \multicolumn{6}{|c|}{ Females } & \multirow[b]{3}{*}{$P$} \\
\hline & \multirow[b]{2}{*}{$n^{\star}$} & \multicolumn{2}{|c|}{ White } & \multirow[b]{2}{*}{$n^{*}$} & \multicolumn{2}{|c|}{ Black } & & \multirow[b]{2}{*}{$n^{*}$} & \multicolumn{2}{|c|}{ White } & \multirow[b]{2}{*}{$n^{*}$} & \multicolumn{2}{|c|}{ Black } & \\
\hline & & Mean & $\mathrm{SD}$ & & Mean & $\mathrm{SD}$ & & & Mean & $\mathrm{SD}$ & & Mean & $\mathrm{SD}$ & \\
\hline 1 & 414 & $17 \cdot 8$ & $1 \cdot 5$ & 124 & $17 \cdot 8$ & 1.9 & 0.77 & 445 & $17 \cdot 3$ & 1.5 & 112 & $17 \cdot 1$ & $1 \cdot 7$ & 0.09 \\
\hline 2 & 1519 & $17 \cdot 2$ & $1 \cdot 4$ & 427 & $17 \cdot 1$ & 1.5 & 0.40 & 1461 & $16 \cdot 8$ & $1 \cdot 4$ & 403 & $16 \cdot 6$ & $1 \cdot 7$ & 0.02 \\
\hline 4 & 1487 & $16 \cdot 4$ & $1 \cdot 4$ & 429 & $16 \cdot 4$ & $1 \cdot 3$ & 0.91 & 1435 & $16 \cdot 3$ & 1.5 & 398 & $16 \cdot 0$ & 1.5 & 0.003 \\
\hline 15 & 376 & $20 \cdot 8$ & $3 \cdot 6$ & 90 & $20 \cdot 8$ & $3 \cdot 1$ & 0.95 & 370 & $21 \cdot 5$ & $3 \cdot 7$ & 84 & $21 \cdot 8$ & $3 \cdot 1$ & 0.53 \\
\hline $18 / 19$ & 1506 & $22 \cdot 3$ & $3 \cdot 8$ & 404 & $22 \cdot 3$ & 3.5 & 0.77 & 319 & $22 \cdot 4$ & 4.9 & 79 & 23.0 & $5 \cdot 7$ & 0.33 \\
\hline 23 & 1653 & $23 \cdot 8$ & $4 \cdot 1$ & 469 & $23 \cdot 7$ & $3 \cdot 8$ & 0.50 & 1517 & $23 \cdot 1$ & $4 \cdot 4$ & 413 & $24 \cdot 5$ & $5 \cdot 4$ & $<0.001$ \\
\hline
\end{tabular}

*Information valid only for individuals interviewed at age 23 years and excluding 150 self-classified as Asian or Amerindian.

Table 3 Mean and standard deviation for BMI $\left(\mathrm{kg} / \mathrm{m}^{2}\right)$ according to family income at birth, and slope index of inequality (SII), among males in the different follow-ups of the 1982 birth cohort study. Pelotas, southern Brazil, 1982 to 2004-2005

\begin{tabular}{|c|c|c|c|c|c|c|c|c|c|c|c|c|}
\hline \multirow[b]{3}{*}{ Age (years) } & \multicolumn{10}{|c|}{ Quintile of family income } & \multirow[b]{3}{*}{$P$} & \multirow[b]{3}{*}{ SII } \\
\hline & \multicolumn{2}{|c|}{$1 \mathrm{st}$} & \multicolumn{2}{|c|}{ 2nd } & \multicolumn{2}{|c|}{ 3rd } & \multicolumn{2}{|c|}{ 4th } & \multicolumn{2}{|c|}{5 th } & & \\
\hline & Mean & $\mathrm{SD}$ & Mean & SD & Mean & $\mathrm{SD}$ & Mean & SD & Mean & $\overline{S D}$ & & \\
\hline 1 & $17 \cdot 4$ & $1 \cdot 8$ & $17 \cdot 8$ & $1 \cdot 7$ & $17 \cdot 5$ & $1 \cdot 6$ & $18 \cdot 1$ & $1 \cdot 5$ & $18 \cdot 0$ & $1 \cdot 4$ & 0.002 & 0.7 \\
\hline 2 & $17 \cdot 0$ & 1.5 & $17 \cdot 0$ & $1 \cdot 4$ & $17 \cdot 1$ & 1.5 & $17 \cdot 3$ & $1 \cdot 4$ & $17 \cdot 3$ & $1 \cdot 3$ & $<0.001$ & 0.4 \\
\hline 4 & $16 \cdot 4$ & $1 \cdot 2$ & $16 \cdot 4$ & $1 \cdot 4$ & $16 \cdot 2$ & $1 \cdot 4$ & $16 \cdot 4$ & $1 \cdot 5$ & $16 \cdot 6$ & $1 \cdot 7$ & 0.02 & 0.3 \\
\hline 15 & $19 \cdot 9$ & $2 \cdot 5$ & $21 \cdot 0$ & $3 \cdot 3$ & $20 \cdot 7$ & $3 \cdot 7$ & $20 \cdot 8$ & $4 \cdot 1$ & $21 \cdot 4$ & $3 \cdot 7$ & 0.02 & $1 \cdot 3$ \\
\hline 18 & $21 \cdot 8$ & $3 \cdot 1$ & $22 \cdot 2$ & $3 \cdot 4$ & $22 \cdot 0$ & $3 \cdot 6$ & $22 \cdot 6$ & $4 \cdot 1$ & $23 \cdot 0$ & $4 \cdot 2$ & $<0.001$ & $1 \cdot 4$ \\
\hline 23 & $23 \cdot 2$ & $3 \cdot 8$ & $23 \cdot 6$ & $3 \cdot 6$ & $23 \cdot 5$ & $4 \cdot 1$ & $24 \cdot 3$ & $4 \cdot 6$ & $24 \cdot 4$ & $4 \cdot 1$ & $<0.001$ & 1.5 \\
\hline
\end{tabular}

Table 4 Mean and standard deviation for BMI $\left(\mathrm{kg} / \mathrm{m}^{2}\right)$ according to family income at birth, and slope index of inequality (SII), among females in the different follow-ups of the 1982 birth cohort study. Pelotas, southern Brazil, 1982 to 2004-2005

\begin{tabular}{|c|c|c|c|c|c|c|c|c|c|c|c|c|}
\hline \multirow[b]{3}{*}{ Age (years) } & \multicolumn{10}{|c|}{ Quintiles of family income } & \multirow[b]{3}{*}{$P$} & \multirow[b]{3}{*}{ SII } \\
\hline & \multicolumn{2}{|c|}{$1 \mathrm{st}$} & \multicolumn{2}{|c|}{ 2nd } & \multicolumn{2}{|c|}{ 3rd } & \multicolumn{2}{|c|}{ 4th } & \multicolumn{2}{|c|}{5 th } & & \\
\hline & Mean & SD & Mean & SD & Mean & SD & Mean & SD & Mean & $\mathrm{SD}$ & & \\
\hline 1 & $16 \cdot 7$ & $1 \cdot 7$ & $17 \cdot 1$ & $1 \cdot 5$ & $17 \cdot 3$ & $1 \cdot 4$ & $17 \cdot 4$ & $1 \cdot 4$ & $17 \cdot 5$ & $1 \cdot 4$ & $<0.001$ & 0.9 \\
\hline 2 & $16 \cdot 6$ & $1 \cdot 4$ & $16 \cdot 6$ & $1 \cdot 4$ & $16 \cdot 7$ & $1 \cdot 3$ & $16 \cdot 9$ & 1.5 & $17 \cdot 0$ & 1.5 & $<0.001$ & 0.5 \\
\hline 4 & $16 \cdot 0$ & $1 \cdot 3$ & $16 \cdot 0$ & $1 \cdot 3$ & $16 \cdot 1$ & $1 \cdot 6$ & $16 \cdot 4$ & $1 \cdot 6$ & $16 \cdot 4$ & $1 \cdot 7$ & $<0.001$ & 0.7 \\
\hline 15 & $21 \cdot 2$ & $3 \cdot 4$ & $21 \cdot 9$ & $3 \cdot 7$ & $21 \cdot 5$ & $3 \cdot 4$ & $21 \cdot 8$ & $3 \cdot 9$ & $21 \cdot 1$ & $3 \cdot 4$ & 0.62 & -0.2 \\
\hline 19 & $22 \cdot 1$ & $4 \cdot 1$ & $22 \cdot 8$ & $4 \cdot 7$ & $21 \cdot 9$ & $3 \cdot 3$ & $23 \cdot 5$ & $7 \cdot 1$ & $21 \cdot 7$ & $3 \cdot 6$ & 0.75 & -0.2 \\
\hline 23 & 23.9 & $5 \cdot 4$ & $24 \cdot 0$ & $5 \cdot 2$ & $23 \cdot 4$ & $4 \cdot 3$ & $23 \cdot 4$ & $4 \cdot 5$ & $22 \cdot 5$ & $3 \cdot 5$ & $<0.001$ & $-1 \cdot 6$ \\
\hline
\end{tabular}

among 23-year-old women, whereas no such association was detected among female adolescents (Table 4). SII estimates showed that differences between rich and poor males were always positive, and increased in magnitude after age 15 years (Table 3). Among females (Table 4), differences were positive during childhood and negative during adolescence and at age 23 years. Differences among men and women in this last follow-up were of equal magnitude, but in opposite directions. Similar patterns were obtained for the prevalence of obesity by income (see Supplementary Materials), although there is greater sampling variability in this outcome than for mean BMI.

Table 5 shows the adjusted effect of skin colour on mean BMI. No differences were detected among white and black males of any age. Among females, whereas mean BMI was higher among white girls at age 4 years, at age 23 years mean BMI was $1.3 \mathrm{~kg} / \mathrm{m}^{2}$ higher among black women, and this effect was independent of family income. We also found a significant interaction between skin colour and sex $(P<0 \cdot 001)$.

\section{Discussion}

The 1982 Pelotas birth cohort is one of the first such studies in developing countries to follow more than 4000 individuals from birth to adulthood ${ }^{(20)}$. Although this is a study with a prospective longitudinal design, many of its analyses have been cross-sectional, and numerous publications have shown the relationship between nutritional status and family income at specific ages ${ }^{(21-26)}$. Based on these results, we have observed that children from richer 
Table 5 Mean and standard deviation for BMI $\left(\mathrm{kg} / \mathrm{m}^{2}\right)$ according to skin colour (black or white), adjusted for family income determined at each follow-up, among males and females in the different follow-ups of the 1982 birth cohort study. Pelotas, southern Brazil, 1982 to 2004-2005

\begin{tabular}{|c|c|c|c|c|c|c|c|c|c|c|}
\hline \multirow[b]{3}{*}{ Age (years) } & \multicolumn{5}{|c|}{ Males } & \multicolumn{5}{|c|}{ Females } \\
\hline & \multicolumn{2}{|c|}{ White } & \multicolumn{2}{|c|}{ Black } & \multirow[b]{2}{*}{$P$} & \multicolumn{2}{|c|}{ White } & \multicolumn{2}{|c|}{ Black } & \multirow[b]{2}{*}{$P$} \\
\hline & Mean & SD & Mean & $\mathrm{SD}$ & & Mean & SD & Mean & $\mathrm{SD}$ & \\
\hline 1 & $17 \cdot 8$ & $1 \cdot 6$ & $17 \cdot 8$ & $1 \cdot 7$ & 0.87 & $17 \cdot 3$ & 1.5 & $17 \cdot 2$ & $1 \cdot 7$ & 0.35 \\
\hline 2 & $17 \cdot 2$ & 1.4 & $17 \cdot 1$ & $1 \cdot 4$ & 0.47 & $16 \cdot 8$ & 1.5 & $16 \cdot \overline{7}$ & 1.5 & $0 \cdot 10$ \\
\hline 4 & $16 \cdot 4$ & $1 \cdot 4$ & $16 \cdot 4$ & $1 \cdot 4$ & 0.51 & $16 \cdot 3$ & 1.5 & $16 \cdot 0$ & 1.5 & 0.008 \\
\hline 15 & $20 \cdot 8$ & 3.5 & $20 \cdot 9$ & $3 \cdot 6$ & 0.82 & $21 \cdot 5$ & $3 \cdot 6$ & $21 \cdot 8$ & $3 \cdot 7$ & 0.58 \\
\hline $18 / 19$ & $22 \cdot 3$ & 3.8 & $22 \cdot 3$ & $3 \cdot 8$ & 0.89 & $22 \cdot 4$ & $5 \cdot 2$ & 23.0 & $5 \cdot 1$ & 0.39 \\
\hline 23 & $23 \cdot 8$ & $4 \cdot 1$ & $23 \cdot 7$ & $4 \cdot 1$ & 0.92 & $23 \cdot 1$ & $4 \cdot 6$ & $24 \cdot 4$ & $4 \cdot 7$ & $<0.001$ \\
\hline
\end{tabular}

families gain more weight during the first year of life ${ }^{(21,22)}$ and that childhood obesity is more frequent among families earning ten or more monthly minimum wages ${ }^{(23)}$. During adolescence, prevalences of overweight and obesity are also higher in higher income categories ${ }^{(24)}$. However, during adulthood, overweight and obesity prevalences are higher among richer men and poorer women $^{(26)}$.

Differences in mean BMI at different ages should be compared with caution, because the distribution changes with age and not only with weight ${ }^{(27)}$. It is reassuring that similar socio-economic patterns were also observed when the outcome was prevalence of obesity, rather than mean BMI. As expected, mean BMI decreased with age during childhood and increased again during adolescence. Unfortunately, we have no measurements between 4 and 15 years of age and are unable to document the onset of the adiposity rebound, a risk factor for later obesity ${ }^{(28)}$, as well as of the adolescent growth spurt which typically occurs up to the age of 15 years. Another limitation is the lack of an objective assessment of puberty.

The present analysis is aimed at consolidating our previously published findings by investigating the association of family income at birth with BMI at different times in life. However, our data do not allow for a longitudinal analysis of evolution of nutritional status, since different subsamples were studied at different times. Notwithstanding, based on an internal analysis of each subsample, we have shown that the difference between rich and poor increased in magnitude while maintaining its direction among males, whereas among females there was an inversion in direction during adolescence. Due to the small income-specific sample sizes, the standard errors are relatively large and the 95\% confidence intervals for any two income groups overlap. However, the ' $P$ ' value for trend indicates that there are significant income gradients in mean BMI for all age groups among males and for most age groups among females.

Prior analyses of this same cohort have shown that the majority of individuals remain in the same socioeconomic group from birth to adult life ${ }^{(25)}$ and that the prevalence of overweight among adults is more closely associated with family income at birth than with change in income from birth to adulthood ${ }^{(26)}$. Therefore, the differences reported in the present study are unlikely to be due to social mobility.

When studying this relationship only among children, an inverse association between economic status and overweight was clearly observable in the USA ${ }^{(29)}$. Whereas overweight and obesity increased primarily among urban populations and in developed countries ${ }^{(9)}$, this increase was equal among children of all income groups in China and greater among the rich in $\mathrm{Brazil}^{(8)}$. Our present results show a positive relationship between BMI and income during childhood for both sexes, which persists to adulthood among males but not for females, for whom the association is inverted. Whereas an inverse association was detected in the USA among female adolescents, the most recent nationwide survey, carried out between 1999 and 2002, showed an increase in prevalence of overweight among male adolescents from medium and high income groups, which all but eliminated the former inverse relationship between overweight and socio-economic level. Complex relationships during adolescence were also observed in the present study, even though data from a probability sample of all Brazilian adults ${ }^{(30)}$ showed an association pattern typical of less developed populations, where overweight and obesity still show a direct relationship with socio-economic status ${ }^{(5)}$.

On the other hand, when analysing this relationship among the Brazilian adult population, while overweight still increased with income among men, this association was less intense among women, with higher prevalence being detected in the intermediate income categories ${ }^{(30)}$. Such complexity was also detected in the present study, where mean BMI increase between 4 and 23 years of age was almost $8 \mathrm{~kg} / \mathrm{m}^{2}$ among men in the highest, and women in the lowest, income quintiles. By contrast, among men in the lowest, and women in the highest, quintiles of the income distribution, mean BMI increase was $6 \cdot 8 \mathrm{~kg} / \mathrm{m}^{2}$ and $6 \cdot 1 \mathrm{~kg} / \mathrm{m}^{2}$, respectively. Men and women in the intermediate income quintile showed identical mean BMI increases $\left(7 \cdot 3 \mathrm{~kg} / \mathrm{m}^{2}\right)$ between 4 and 23 years of age. 
The most recent review of the relationship between socio-economic status and obesity ${ }^{(3)}$ included studies of adult populations (18 years or older) published between 1988 and 2004, updating the review by Sobal and Stunkard ${ }^{(5)}$. Based on these data, the authors found that the majority of associations were negative among women, with lower socio-economic level being associated with larger body volume. For men from countries of high or medium HDI, either no association was found or associations were negative for high-HDI and positive for medium-HDI countries. Only three studies including the male population of low-HDI countries found positive associations between economic level and obesity ${ }^{(3)}$. Our present results are therefore in agreement with the findings of this review; i.e. family income and BMI are negatively or inversely associated among women, and positively or directly associated among men.

Complex patterns in this association have also been found in studies from other developing countries ${ }^{(4)}$, or when analysing nationwide Brazilian studies ${ }^{(31)}$. A review of studies from developing countries has concluded that: (i) obesity cannot be considered a problem affecting only the highest socio-economic strata; (ii) there is a trend towards increasing obesity in poorer countries undergoing an increase in gross domestic product; and (iii) a change towards increased obesity among poorer women can be seen as a first stage in a country's economic development ${ }^{(4)}$. In Brazil, prevalence of obesity has been increasing among both men and women since the end of the last century, and this increase has been taking place primarily among the lower income groups. On the other hand, the evolution of female obesity trends indicates that the prevalence of obesity has been decreasing among women in the highest income quintiles $^{(31)}$.

Of special interest among our results are the finding related to skin colour. Because of intense miscegenation, the accepted approach in Brazilian ethnicity research is to ask about skin colour because concepts such as 'race' or 'ethnic group' make little sense ${ }^{(32)}$. There were no differences in mean BMI observed between men selfclassified as white, black or mixed in any of the various follow-ups. On the other hand, in adulthood black or mixed women were fatter than white women. Notwithstanding, black or mixed colour children were thinner than white children at age 4 years. Differences in obesity prevalence according to race have been detected in the $\mathrm{USA}^{(11,33)}$, where they also occur to different extents among men and women ${ }^{(34)}$. However, higher prevalence of obesity has been observed in ethnic minorities since childhood $^{(35)}$ through to adulthood $^{(33)}$. The effect of skin colour on nutritional status has not been as extensively studied in the Brazilian population; however, our present results, which show higher mean BMI among adult black and mixed women, are in agreement with a study conducted in Rio de Janeiro that showed weight gain across a 10-year period was also greater among non-white women, even after adjustment for socioeconomic conditions throughout life ${ }^{(10)}$. The reasons for higher BMI among black women are unclear; previous analyses of the cohort data at 23 years did not suggest any differences in dietary ${ }^{(36)}$ or physical activity ${ }^{(37)}$ patterns compatible with the differences reported above.

\section{Conclusions}

Although based on cross-sectional data, the present results allow us to identify the periods of life in which individuals of both sexes are most susceptible to the effects of socio-economic conditions on nutritional status. Our results show income-dependent differences in BMI from childhood to adolescence in both males and females, suggesting therefore that socio-economic conditions can have an effect on the prevalence of overweight and obesity. These differences are complex, being initially related to greater prevalence of undernutrition in the poor during early life. As cohort members grew in a rapidly changing society - including major changes in diet and physical activity - these socio-economic patterns in anthropometric status changed and some of the earlier differentials were reversed. When interpreted in the light of the nutritional profile of the Brazilian population ${ }^{(30)}$, our results indicate the need for public policies based on an understanding of the complex changes in the nutritional status of different social strata.

\section{Acknowledgements}

This article is based on data from the study 'Pelotas birth cohort, 1982' conducted by the Postgraduate Program in Epidemiology at the Universidade Federal de Pelotas. The 1982 birth cohort study is currently supported by the Wellcome Trust Initiative entitled 'Major Awards for Latin America on Health Consequences of Population Change'. Previous phases of the study were supported by the International Development Research Centre, WHO, the Overseas Development Administration, the European Union, the National Support Program for Centers of Excellence (PRONEX), the Brazilian National Research Council (CNPq) and the Brazilian Ministry of Health. There are no conflicts of interest. D.P.G. and C.G.V. conceived the paper, conducted the analysis and wrote the manuscript. A.M. and B.L.H. contributed in the analyses and F.C.B. contributed to the design of the study. All authors revised and approved the final version of the paper for publication.

\section{Supplementary Materials}

For Supplementary Materials for this article, please visit http://dx.doi.org/10.1017/S1368980012003229 


\section{References}

1. World Health Organization (2000) Obesity: Preventing and Managing the Global Epidemic. WHO Technical Report Series no. 894. Geneva: WHO.

2. Ball K \& Crawford D (2005) Socioeconomic status and weight change in adults: a review. Soc Sci Med 60, 1987-2010.

3. McLaren L (2007) Socioeconomic status and obesity. Epidemiol Rev 29, 29-48.

4. Monteiro CA, Moura EC, Conde WL et al. (2004) Socioeconomic status and obesity in adult populations of developing countries: a review. Bull World Health Organ 82, 940-946.

5. Sobal J \& Stunkard AJ (1989) Socioeconomic status and obesity: a review of the literature. Psychol Bull 105, 260-275.

6. Parsons TJ, Power C, Logan S et al. (1999) Childhood predictors of adult obesity: a systematic review. Int J Obes Relat Metab Disord 23, Suppl. 8, S1-S107.

7. Cole TJ, Bellizzi MC, Flegal KM et al. (2000) Establishing a standard definition for child overweight and obesity worldwide: international survey. BMJ 320, 1240-1243.

8. Wang Y, Monteiro C \& Popkin BM (2002) Trends of obesity and underweight in older children and adolescents in the United States, Brazil, China, and Russia. Am J Clin Nutr $\mathbf{7 5}$, 971-977.

9. Wang $\mathrm{Y}$ \& Lobstein $\mathrm{T}$ (2006) Worldwide trends in childhood overweight and obesity. Int J Pediatr Obes $\mathbf{1}$, $11-25$.

10. Chor D, Faerstein E, Kaplan GA et al. (2004) Association of weight change with ethnicity and life course socioeconomic position among Brazilian civil servants. Int J Epidemiol 33, 100-106.

11. Cossrow N \& Falkner B (2004) Race/ethnic issues in obesity and obesity-related comorbidities. J Clin Endocrinol Metab 89, 2590-2594.

12. Barros FC, Victora CG \& Vaughan JP (1990) The Pelotas (Brazil) birth cohort study 1982-1987: strategies for following up 6000 children in a developing country. Paediatr Perinat Epidemiol 4, 205-220.

13. Victora CG, Barros FC, Lima RC et al. (2003) The Pelotas birth cohort study, Rio Grande do Sul, Brazil, 1982-2001. Cad Saude Publica 19, 1241-1256.

14. Victora CG \& Barros FC (2006) Cohort profile: the 1982 Pelotas (Brazil) birth cohort study. Int J Epidemiol 35, 237-242.

15. Barros FC, Victora CG, Horta BL et al. (2008) Methodology of the Pelotas birth cohort study from 1982 to 2004-5, Southern Brazil. Rev Saude Publica 42, Suppl. 2, 7-15.

16. Lohman TG, Roche AF \& Martorell R (1988) Anthropometric Standardization Reference Manual. Champaign, IL: Human Kinetics.

17. de Onis M, Garza C, Victora CG et al. (2004) The WHO Multicentre Growth Reference Study: planning, study design, and methodology. Food Nutr Bull 25, Suppl. 1, S15-S26.

18. de Onis M, Onyango AW, Borghi E et al. (2007) Development of a WHO growth reference for school-aged children and adolescents. Bull World Health Organ 85 , 660-667.

19. Mackenbach JP \& Kunst AE (1997) Measuring the magnitude of socio-economic inequalities in health: an overview of available measures illustrated with two examples from Europe. Soc Sci Med 44, 757-771.
20. Harpham T, Huttly S, Wilson I et al. (2003) Linking public issues with private troubles: panel studies in developing countries. J Int Dev 15, 353-363.

21. Victora CG, Barros FC, Vaughan JP et al. (1987) Birthweight, socio-economic status and growth of Brazilian infants. Ann Hum Biol 14, 49-57.

22. Victora CG, Huttly SR, Barros FC et al. (1992) Maternal education in relation to early and late child health outcomes: findings from a Brazilian cohort study. Soc Sci Med 34, 899-905.

23. Post CL, Victora CG, Barros FC et al. (1996) Infant malnutrition and obesity in two population-based birth cohort studies in southern Brazil: trends and differences. Cad Saude Publica 12, Suppl. 1, 49-57.

24. Monteiro PO, Victora CG, Barros FC et al. (2003) Birth size, early childhood growth, and adolescent obesity in a Brazilian birth cohort. Int J Obes Relat Metab Disord 27, $1274-1282$.

25. Barros AJ, Victora CG, Horta BL et al. (2006) Effects of socioeconomic change from birth to early adulthood on height and overweight. Int J Epidemiol 35, 1233-1238.

26. Gigante DP, Minten GC, Horta BL et al. (2008) Nutritional evaluation follow-up of the 1982 birth cohort, Pelotas, Southern Brazil. Rev Saude Publica 42, Suppl. 2, 60-69.

27. Flegal KM \& Ogden CL (2011) Childhood obesity: are we all speaking the same language? Adv Nutr 2, issue 2, 159S-166S.

28. Cole TJ (2004) Children grow and horses race: is the adiposity rebound a critical period for later obesity? $B M C$ Pediatr 12, 4-6.

29. Wang Y \& Zhang Q (2006) Are American children and adolescents of low socioeconomic status at increased risk of obesity? Changes in the association between overweight and family income between 1971 and 2002. Am J Clin Nutr 84, 707-716.

30. Instituto Brasileiro de Geografia e Estatística (2004) Pesquisa Orçamentos Familiares 2002-2003. Análise da disponibilidade domiciliar de alimentos e do estado nutricional no Brasil. Rio de Janeiro: IBGE.

31. Monteiro CA, Conde WL \& Popkin BM (2007) Incomespecific trends in obesity in Brazil: 1975-2003. Am J Public Health 97, 1808-1812.

32. Pena SD, Di Pietro G, Fuchshuber-Moraes M et al. (2011) The genomic ancestry of individuals from different geographical regions of Brazil is more uniform than expected. PLoS One 6, e17063.

33. Zhang Q \& Wang Y (2004) Socioeconomic inequality of obesity in the United States: do gender, age, and ethnicity matter? Soc Sci Med 58, 1171-1180.

34. McTigue KM, Garrett JM \& Popkin BM (2002) The natural history of the development of obesity in a cohort of young US adults between 1981 and 1998. Ann Intern Med 18, $857-864$

35. Nesbitt SD, Ashaye MO, Stettler N et al. (2004) Overweight as a risk factor in children: a focus on ethnicity. Ethn Dis 14, 94-110.

36. Olinto MT, Willett WC, Gigante DP et al. (2011) Sociodemographic and lifestyle characteristics in relation to dietary patterns among young Brazilian adults. Public Health Nutr 14, 150-159.

37. Azevedo MR, Horta BL, Gigante DP et al. (2008) Factors associated to leisure-time sedentary lifestyle in adults of 1982 birth cohort, Pelotas, Southern Brazil. Rev Saude Publica 42, 70-77. 